\title{
Thermally induced reaction and diffusion of carbon films on $\mathrm{Ni}(111)$ and $\mathrm{Ni}(100)$
}

\author{
A. Wiltner, Ch. Linsmeier* \\ Max-Planck-Institut für Plasmaphysik, EURATOM Association, \\ Boltzmannstrasse 2, D-85748 Garching b. München, Germany
}

\begin{abstract}
Thin carbon films on $\mathrm{Ni}(111)$ and $\mathrm{Ni}(100)$ and the reactive and diffusive interactions between film and substrate are investigated using X-ray photoelectron spectroscopy (XPS). The carbon films are deposited from the vapor phase with the substrates at room temperature. After deposition the films contain mainly elemental carbon. Restricted only to the carbon-nickel interface carbidic carbon is observed. Carbon films of various thicknesses between 0.4 and $3.2 \mathrm{~nm}$ are investigated after thermal treatments up to $970 \mathrm{~K}$. The $\mathrm{C} 1 s$ signal intensities are used for chemical analysis, both in a qualitative and quantitative way. The initially formed carbide partially decomposes between 400 and $570 \mathrm{~K}$. Additional carbide formation sets in again, combined with incipient carbon diffusion, at higher temperatures. Carbon diffusion into the bulk leads to a decreasing $\mathrm{C} 1 s$ signal intensity until the carbon is almost completely lost into the bulk.
\end{abstract}

Keywords: Carbon, Nickel, Carbides, surface chemical reaction, X-ray photoelectron spectroscopy

\section{INTRODUCTION}

The binary system carbon/nickel is studied by various authors with respect to the application of $\mathrm{Ni}$ as a catalyst [1-19]. Eizenberg et al. [1, 2] doped different Ni crystal planes with carbon by holding the sample in a quartz capsule filled with graphite powder at high temperatures. The authors reported a decreasing carbon signal with increasing annealing temperature measured by Auger electron spectroscopy (AES). Depending on the surface orientation they observed a graphite monolayer condensation in a temperature range of $100 \mathrm{~K}$ until the carbon was completely lost into the bulk. Other authors prepared carbon films by thermal decomposition of hydrocarbons or carbon monoxide [3-11, 14-16]. Various measurement techniques and crystal planes, respectively, were used. McCarthy [3] found a carbide layer after decomposition of ethene on $\mathrm{Ni}(100)$, and measured the thermal behavior with AES and low energy electron diffraction (LEED). Schouten et al. [4] decomposed methane on $\mathrm{Ni}(110)$ and analyzed the solution of carbon into $\mathrm{Ni}$ using AES. Zdansky et al. deposited carbon by decomposition of ethene followed by $\mathrm{CO}$ adsorption on the $\mathrm{C}$ precovered $\mathrm{Ni}(100)$ surface [5]. They reported a surfaceto-bulk carbide transformation induced by CO adsorption. Rosei et al. measured the structure of graphitic $\mathrm{C}$ on $\mathrm{Ni}(111)$ by surface extended energy loss fine structure (SEELFS) [6]. The graphite layer was deposited by thermal decomposition of $\mathrm{CO}$ at $570 \mathrm{~K}$. Steinrück et al. observed the adsorption and temperature dependent decomposition of hydrocarbons (propene, methanol) on $\mathrm{Ni}(100)$ by fast X-ray photoelectron spectroscopy (XPS) studies $[7,8]$. Several investigations dealt with a surface reconstruction called 'clock reconstruction', observed on $\mathrm{Ni}(100)$ and $\mathrm{Ni}(111)$ measured by scanning tunneling mi-

\footnotetext{
*Tel.: +49-89-3299 2285, Fax.: +49-89-3299 962285,
}

linsmeier@ipp.mpg.de croscopy (STM), LEED and photoemission techniques [9-13]. This reconstruction was explained by carbide formation. Both crystallographic orientations show this surface process after $\mathrm{C}$ deposition of $0.2-0.6$ monolayers (ML). Carbon deposited above these coverages leads to graphite formation. Nakamura et al. observed the growth of carbon and carbide formation on $\mathrm{Ni}$ depending on crystal plane and carbon source $\left(\mathrm{CO}\right.$ and $\left.\mathrm{C}_{2} \mathrm{H}_{4}\right)$ by STM, AES and LEED [14-16]. On the Ni(977) surface they observed the carbidic $\mathrm{C}$ up to a coverage of $1.8 \mathrm{ML}$. Levenson et al. [17-19] prepared 'the inverse system' by depositing thin $\mathrm{Ni}$ films on graphite. They found $\mathrm{Ni}_{3} \mathrm{C}$ at room temperature followed by carbide decomposition at temperatures below $470 \mathrm{~K}$ using XPS and AES. The carbide was completely decomposed at temperatures above $670 \mathrm{~K}$.

Another topic of interest described in the literature is the observation of binding energy shifts due to varying cluster sizes. Egelhoff et al. [20, 21] deposited transition metals $(\mathrm{Cu}, \mathrm{Ni}, \mathrm{Pd})$ on carbon substrates and measured the binding energy shift in the metal valence band regions using ultraviolet photoelectron spectroscopy (UPS) and in the core-level regions by XPS. The authors reported continuous binding energy shifts with increasing metal cluster sizes. No shift in the binding energy of the carbon signal was observed. In particular, no carbide formation on $\mathrm{Ni}$, potentially visible as binding energy shifts, was observed.

In this work carbon films are deposited from the vapor phase produced by an electron beam evaporation source. The film deposition is performed by holding the substrate at room temperature, any decomposition reaction of molecular precursors, common to all previously conducted studies described in the literature above, is not necessary. The surface composition and chemistry is monitored in situ by XPS analysis. Films prepared under these conditions show a thin carbide layer at the adsorbate--metal interface and additionally elemental (not reacted) carbon. Such behavior was observed also on various other substrates [22-26]. Carbon film thick- 


\begin{tabular}{|ll|}
\hline carbide & $\Delta \mathrm{G}_{f}^{0}(\mathrm{eV})$ \\
\hline \hline $\mathrm{TiC}$ & -1.87 \\
$\mathrm{Be}_{2} \mathrm{C}$ & -1.19 \\
$\mathrm{SiC}$ & -0.73 \\
$\mathrm{WC}$ & -0.40 \\
$\mathrm{~W}_{2} \mathrm{C}$ & -0.23 \\
$\mathrm{Ni}_{3} \mathrm{C}$ & +0.66 \\
\hline
\end{tabular}

TABLE I: Free energy of formation (Gibbs function) at $300 \mathrm{~K}$ [27] for carbides described in [22-25] and $\mathrm{Ni}_{3} \mathrm{C}$.

nesses range from the submonolayer region up to several nanometers. The maximum initial film thickness in our experiments is only limited by the information depth of the applied analysis method, XPS. Since we are interested in the interfacial properties between carbon layer and $\mathrm{Ni}$, the maximum film thicknesses applied here are in the range of a few nanometers. The deposition of elemental carbon at room temperature allows a detailed study of processes like growth mode and binding energy shifts immediately after film deposition. In addition, the dependence of different processes (carbon diffusion, growth mode, binding energy shifts) on the substrate temperature and film thickness can be investigated in detail. The chosen analysis technique, XPS, provides information on the near-surface region due to the limited escape depth of the photoelectrons and is a sensitive tool to study chemical reactions. The binding energies of electrons in the core levels are affected by the chemical state of the respective element. Therefore, core-level shifts provide both an identification of elements involved in chemical surface reactions and the changes in the chemical binding states. In addition, binding energy shifts are caused by processes like cluster size effects or surface rearrangements. In addition to $\mathrm{Ni}$ we investigate carbon films on $\mathrm{W}, \mathrm{Be}, \mathrm{Ti}$ and $\mathrm{Si}$, as reported earlier [22-25]. The reactivity of carbon films depends on thermodynamic properties of the respective carbides. In all substrate cases investigated by our group up to now, the reactivity of carbon films correlates with the thermodynamic properties of the respective carbides. The enthalpies of formation for carbides of $\mathrm{W}, \mathrm{Si}, \mathrm{Be}$, and $\mathrm{Ti}$ are all exothermic. However, $\mathrm{Ni}_{3} \mathrm{C}$ exhibits endothermic behavior at temperatures up to $800 \mathrm{~K}$ [27]. The free energies of formation (Gibbs functions, $\Delta G_{f}^{0}$ ) for the discussed carbides are shown in Table I. Keeping the thermodynamic properties in mind a comparison of the thermal behavior of these binary systems is interesting. In this work we investigate the carbide formation on Ni crystal planes (111) and (100), and we will compare their chemical reactivity with the other substrates.

\section{EXPERIMENTAL}

The XPS experimental setup consists of analysis and preparation chambers connected by a UHV valve with base pressures better than $1 \times 10^{-8} \mathrm{~Pa}$. The preparation chamber is equipped with an Omicron EFM3 electron beam evaporation source and a quadrupole mass spectrometer (QMS). The analysis chamber consists of a PHI 5600 XPS system and an ion gun (Specs IQE 12/38). To achieve highest resolution monochromatic $\mathrm{Al} \mathrm{K} \alpha$ radiation is used. The hemispherical analyzer is driven at pass energies of $2.95 \mathrm{eV}$ for high resolution scans and at $93.90 \mathrm{eV}$ for survey scans. The binding energies are calibrated with respect to the $\mathrm{Au} 4 f_{7 / 2}$ peak at $84.00 \mathrm{eV}$. The linearity of the binding energy scale is calibrated using the $\mathrm{Cu} 2 p_{3 / 2}(932.7 \mathrm{eV}), \mathrm{Ag} 3 d_{5 / 2}(368.3 \mathrm{eV})$ and Au $4 f_{7 / 2}$ lines [28]. The analyzer entrance lens is set to an analysis spot size of $0.8 \mathrm{~mm}$ in diameter. The polished $\mathrm{Ni}(111)$ and $\mathrm{Ni}(100)$ crystals (diameter $1 \mathrm{~cm}$ ) are cleaned using $\mathrm{Ar}^{+}$sputtering ( $3 \mathrm{keV}$ ) and annealing (up to $970 \mathrm{~K}$ ) cycles until no impurities are observed in the survey spectra. Next to the respective Ni crystal a gold foil is fixed on the sample holder for periodic checks of the Au $4 f_{7 / 2}$ peak position. Carbon deposition is performed from a high purity graphite rod (99.999\%, Goodfellow) with the Ni crystals at room temperature $(300 \mathrm{~K})$. During the carbon deposition the pressure is better than $1 \times 10^{-7} \mathrm{~Pa}$.

\section{DATA ANALYSIS}

For the analysis of the XPS signal intensities and peak fitting the PHI MultiPak [29] software package is used. A Shirley background is subtracted from the spectra shown in this paper. In the peak fitting procedures for the $\mathrm{C} 1 \mathrm{~s}$ signals symmetric Gauss-Lorentz functions are used. For the Ni $2 p$ peaks we don't apply a peak fitting procedure. Photoelectron intensities are determined by integrating the spectra and subtraction of a Shirley background. For intensities of the different contributions to the $\mathrm{C} 1 s$ signals the integrals of the fitted functions are used. The carbon layer thickness is evaluated using an electron attenuation length of $1.082 \mathrm{~nm}\left(\lambda_{N i}^{C}\right)$ for $\mathrm{Ni} 2 p_{3 / 2}$ and $1.494 \mathrm{~nm}\left(\lambda_{C}^{C}\right)$ for C $1 s$ photoelectrons, calculated with the 'universal' Seah-Dench equation (1), as reported in [30].

$$
\lambda\left(E_{S}^{F}\right)=\frac{538}{E_{S}^{2}} a+0.41 a^{3 / 2} E_{S}^{1 / 2}
$$

The parameters are the kinetic energy of the photoelectrons $\left(E_{S}\right.$ in $\left.\mathrm{eV}\right)$ and the atom diameter ( $a$ in $\left.\mathrm{nm}\right)$. We use a density of $1.8 \mathrm{~g} / \mathrm{cm}^{3}$ for the carbon layers [22, 31]. From this a thickness of $0.22 \mathrm{~nm}$ for 1 monolayer of carbon is calculated. For the determination of the layer thickness we use both substrate $\left(I_{S}\right)$ and layer intensities $\left(I_{C}\right)$ as well as the sensitivity factors $S_{N i}$ and $S_{C}$ for our XPS system [32]. The measured intensities $I_{N i}$ and 
$I_{C}$ are usually correlated to the layer thickness $d_{C}$ by the following equations.

$$
\begin{gathered}
I_{N i}=I_{N i}^{\infty} \exp \left(-\frac{d_{C}}{\lambda_{N i}^{C} \cos \theta}\right) \\
I_{C}=I_{C}^{\infty}\left[1-\exp \left(-\frac{d_{C}}{\lambda_{C}^{C} \cos \theta}\right)\right]
\end{gathered}
$$

Thereby $\theta$ is the angle between the sample surface normal and the analyzer. The intensities $I_{N i}^{\infty}, I_{C}^{\infty}$ corresponding to the pure metal and an extended carbon layer are not known for each specific measurement, because the sample is moved for carbon layer deposition from the analysis to the preparation chamber leading to different sample positions in front of the analyzer. Moreover, the photon fluxes differ for separate measurement runs. These uncertainties in the intensity measurements are avoided by using the ratio of the substrate $\left(I_{N i}\right)$ and layer intensities $\left(I_{C}\right)$ from the same XPS spectrum. The ratio of the sensitivity factors corresp , mr4d gonds to the ratio of the intensities of pure elemental $\mathrm{Ni}\left(I_{N i}^{\infty}\right)$ and carbon $\left(I_{C}^{\infty}\right)$ samples (equation 3).

$$
\frac{I_{N i}^{\infty}}{I_{C}^{\infty}}=\frac{S_{N i}}{S_{C}}
$$

From these equations results the relation between intensities and carbon layer thickness $d_{C}$ which is given in equation 4.

$$
\begin{aligned}
& \underbrace{\frac{I_{C}}{I_{N i}} \cdot \frac{S_{N i}}{S_{C}}}_{r}=\underbrace{\left[\exp \left(\frac{1}{\lambda_{N i}^{C} \cos \theta}\right)\right]^{d_{C}}}_{m} \\
& -\underbrace{\left[\exp \left(\frac{1}{\lambda_{N i}^{C} \cos \theta}-\frac{1}{\lambda_{C}^{C} \cos \theta}\right)\right]}_{n}
\end{aligned}
$$

The carbon layer thickness $d_{C}$ is evaluated by numerical analysis of equation 5 using the Mathcad software package.

$$
m^{d_{C}}-n^{d_{C}}-r=0 \longrightarrow d_{C}
$$

\section{RESULTS}

\section{A. Carbon films at room temperature}

We deposit carbon films from submonolayer coverages up to several nanometers. Performing the film deposition from the vapor phase at room temperature allows a determination of the growth mode and a detailed deconvolution of the $\mathrm{C} 1 s$ signals into chemical states. The growth mode can be determined either by a determination of layer and substrate intensity ratios or by a detailed investigation of the inelastic background at the low kinetic

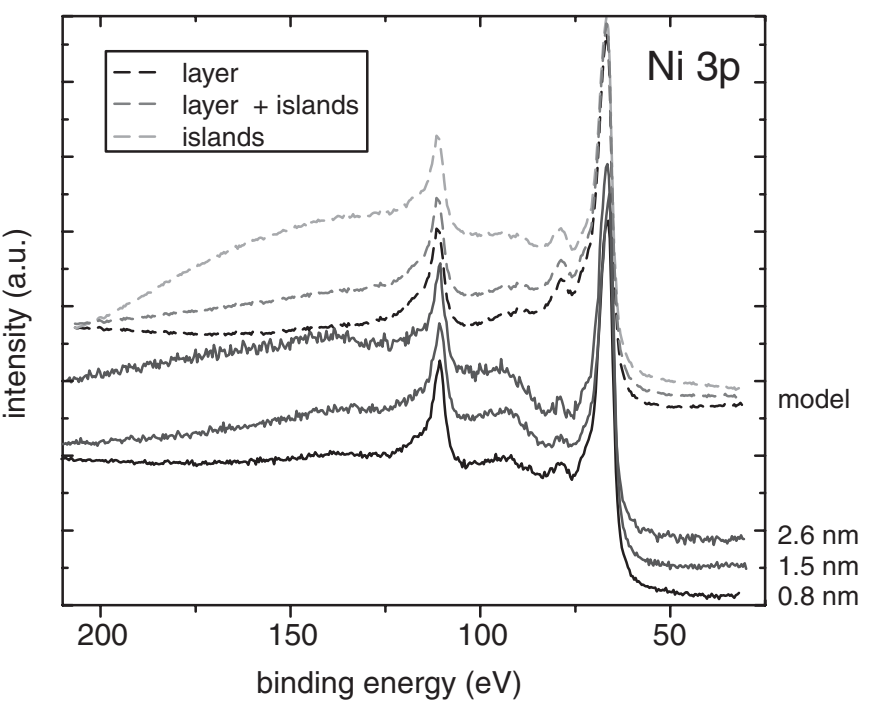

FIG. 1: Comparison of measured (lower part) and calculated survey spectra (upper part) of the Ni $3 p$ region applying Tougaard's model for layer, layer plus island and island growth modes.

energy region of a XPS line (Tougaard's model). The ratio of intensities was already used for the layer thickness estimation under an assumption of a layer growth mode. Since a direct measurement of the layer morphology by other analysis techniques than XPS is not available, we use Tougaard's model as an independent method for the determination of the growth mode. In Figure 1 the $\mathrm{Ni} 3 p$ signal region of carbon layers on $\mathrm{Ni}$ and calculated survey spectra are plotted. The calculated spectra are obtained by using the software package Quases which includes Tougaard's model [33-35]. This model describes the influence of the film morphology on the inelastic background at the lower kinetic electron energy side of a photoelectron peak. It is sensitively affected by the growth mode. According to Tougaard's model, we examine the inelastic background in the survey scans at the low kinetic energy side of the $\mathrm{Ni} 3 p$ peak at $66 \mathrm{eV}$, since no additional signal intensity from other elements is observed in this binding energy region. A comparison of carbon films with increasing thickness indicates a layer growth mode up to $\sim 1.3 \mathrm{~nm}$. For thicker carbon films the examination of the background region concludes a layer followed by island growth mode. In particular, the island growth mode can be excluded from this comparison, since the respective distinct background increase, as calculated according to Tougaard's model (uppermost curve in Fig. 1) is not observed in the measured spectra. In the following we will focus on the XPS analysis of the carbon layers after room temperature deposition. For the separation of chemically different carbon binding states in the $\mathrm{C} 1 s$ signal we use peak fitting routines of the MultiPak software package. During the fit procedure, we use known binding energies of graphitic and disordered graphitic carbon at $284.2(\mathrm{FWHM}=1.0 \mathrm{eV})$ and $285.1 \mathrm{eV}$ 
$(\mathrm{FWHM}=1.4 \mathrm{eV})$, respectively. These binding energies are identified by measuring carbon films on $\mathrm{Au}$. In this system, no reaction or diffusion phenomena are observed up to annealing temperatures of $1200 \mathrm{~K}$ [23]. In the case of carbon films on $\mathrm{Ni}$ an additional peak at $283.5 \mathrm{eV}$ is necessary to reproduce the measured $\mathrm{C} 1 s$ spectra in the fit procedure. The peak separation of $0.9 \mathrm{eV}$ between both graphitic species and the peak position of the graphitic carbon at $284.2 \mathrm{eV}$ were kept constant during the fitting procedure, only the third component was allowed to shift in its position. This third signal component is assigned to the nickel carbide. The binding energy value is in good agreement with $\mathrm{Ni}_{3} \mathrm{C}$ data reported in literature $[5,18,36]$. The $\mathrm{C} 1 s$ spectra of two carbon films of different thicknesses on $\mathrm{Ni}(111)$ and their deconvolution results are shown in Fig. 2. In Fig. 2a, the results of a thin film $(0.2 \mathrm{~nm}, \sim 1 \mathrm{ML})$ clearly show an additional peak at the lower binding energy side of the two elemental peaks, indicating the carbide. Larger amounts of carbon deposited on the Ni surface lead to a smaller carbide signal. Fig. $2 \mathrm{~b}$ shows the $\mathrm{C} 1 s$ region for a total carbon film thickness of $1.9 \mathrm{~nm}$ after RT deposition. The elemental carbon consists of the graphitic modification leading to a photoelectron peak at $284.2 \mathrm{eV}$, and a disordered graphitic modification with a signal at higher binding energy. This peak is visible as a shoulder already in Fig. 2a of the 1 ML C film and becomes more pronounced for the greater film thickness (Fig. 2b). A detailed quantification of the $\mathrm{C} 1 s$ signal on $\mathrm{Ni}(111)$ and $\mathrm{Ni}(100)$ using graphitic, disordered graphitic and carbidic carbon, as described above, is shown in Fig. 3. This figure contains the results from both the $\mathrm{Ni}(111)$ (grey symbols) and $\mathrm{Ni}(100)$ (black and open symbols). Both substrates exhibit a similar $\mathrm{C} 1 s$ signal composition with increasing carbon layer thickness. Neither in the development of the elemental fractions, nor in the carbide fraction, differences are visible for the two Ni surfaces.

Although nickel carbide is an endothermic compound, a nickel carbide peak is measured directly after depositing $\mathrm{C}$ on substrates at RT. The carbide amount is small and the respective peak intensity at $283.5 \mathrm{eV}$ decreases rapidly on deposition of additional carbon. The maximum fraction of carbide in the carbon peak is $65 \%$. After carbon deposition of $1 \mathrm{ML}$ we identify $45 \%$ carbide within the $\mathrm{C} 1 s$ signal. Additional deposited carbon is in the elemental state leading to smaller carbide intensities. The elemental carbon attenuates the photoelectrons coming from the film-substrate interface. This observation can be explained by a carbide layer restricted to the interface, increasingly covered by elemental carbon. As mentioned above, the elemental carbon shows graphitic and disordered graphitic carbon. The ratio of disordered/graphitic $\mathrm{C}$ starts at 0.3 and reaches 0.6 in maximum after deposition of $\sim 8$ ML.

As described by Mason in [37] and for measurements of transition metals on $\mathrm{C}$ by Egelhoff et al. [20, 21], a continuous binding energy shift of the respective core levels to lower or higher values is observed upon increasing de-

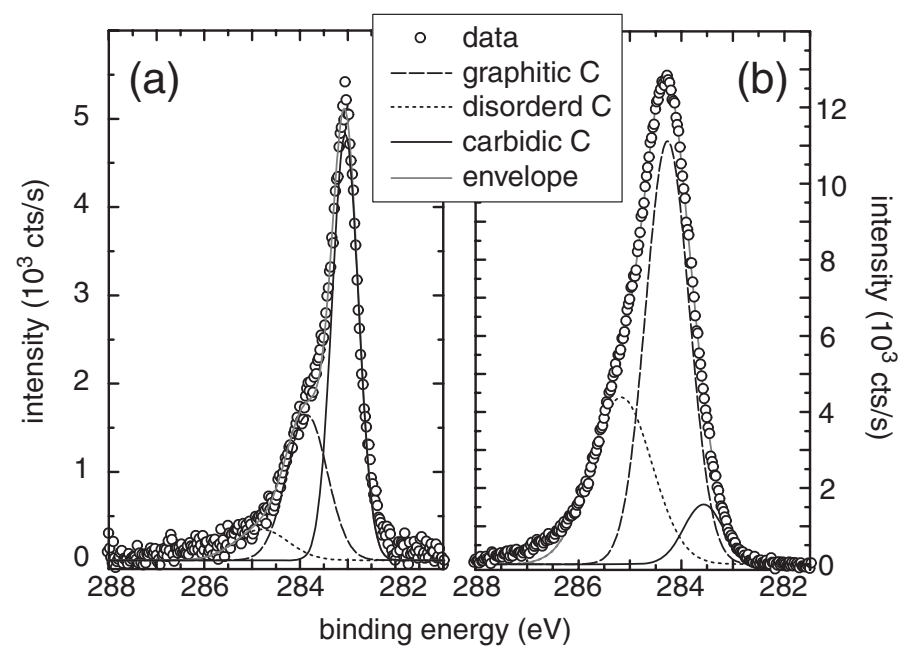

FIG. 2: C $1 s$ signals and the components identified using the MultiPak fit routines. The signals show elemental carbon consisting of graphitic (- -) at $284.2 \mathrm{eV}$ and disordered graphitic $(\cdots)$ carbon at $285.1 \mathrm{eV}$. The best result is obtained using carbidic carbon (-) at $283.0 \mathrm{eV}$ (a) and $283.5 \mathrm{eV}$ (b). The data $(\mathrm{O})$ after Shirley background subtraction and the sum of all components (grey line) are shown. The thicknesses of the carbon layers on $\mathrm{Ni}(111)$ are $0.2 \mathrm{~nm}$ (a) and $1.9 \mathrm{~nm}$ (b), respectively.

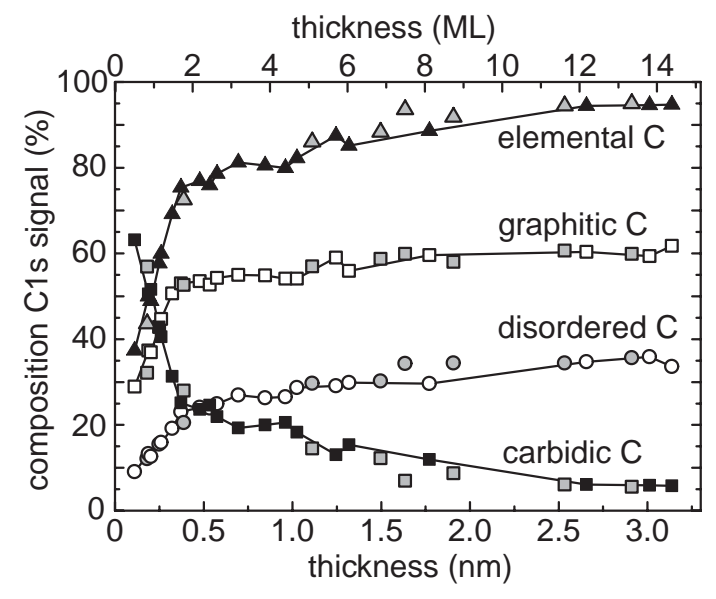

FIG. 3: Evolution of the C $1 s$ signal components with increasing carbon film thickness on $\mathrm{Ni}(100)$ and $\mathrm{Ni}(111)$. The $\mathrm{C} 1 \mathrm{~s}$ signals show graphitic $(\square)$, disordered graphitic (O), elemental $(\boldsymbol{\Lambda})$ and carbidic $(\boldsymbol{\square})$ carbon. Grey symbols represent the data on $\mathrm{Ni}(111)$, all others on $\mathrm{Ni}(100)$. Only the $\mathrm{Ni}(100)$ data points are connected by lines. Within the experimental scatter there is no deviation between $\mathrm{Ni}(100)$ and $\mathrm{Ni}(111)$ data points.

position. This binding energy shift was explained by a cluster size effect. Following this interpretation, isolated particles exhibit different peak positions as larger clusters or completed layers. We also find a binding energy shift for the carbidic $\mathrm{C}$ peak position compared to the graphite fraction at $284.2 \mathrm{eV}$. The graphite peak position is constant in the observed coverage region from submonolayer 


\begin{tabular}{|llll|}
\hline $\mathrm{C} 1 s$ & $\mathrm{BE}^{\text {exp }}(\mathrm{eV})$ & $\mathrm{BE}^{\text {lit }}(\mathrm{eV})$ & References \\
\hline \hline graphitic & 284.2 & 284.2 & {$[23]$} \\
& & $284.3-284.5$ & {$[32]$} \\
disordered & 285.1 & 285.2 & {$[23]$} \\
& & 285.1 & {$[48]$} \\
carbidic & 283.5 & $283.6^{a}$ & {$[5,18]$} \\
\hline \hline $\mathrm{Ni} 2 p_{3 / 2}$ & $\mathrm{BE}^{\text {exp }}(\mathrm{eV})$ & $\mathrm{BE}^{\text {lit }}(\mathrm{eV})$ & References \\
\hline \hline $\mathrm{Ni}$ & 852.8 & 852.7 & {$[32]$} \\
& & 852.9 & {$[36]$} \\
$\mathrm{Ni}_{3} \mathrm{C}$ & 853.0 & 853.8 & {$[36]$} \\
\hline
\end{tabular}

TABLE II: Peak positions determined in this work $\left(\mathrm{BE}^{\exp }\right)$ compared to literature data $\left(\mathrm{BE}^{l i t}\right){ }^{a}$ The literature value is shifted with respect to the graphite peak position, measured in our work at $284.2 \mathrm{eV}$.

up to $3.2 \mathrm{~nm}$ carbon layers. As already mentioned above, we kept the BE separation between the graphitic and disordered graphitic C 1s components fixed. Only the carbidic peak position was allowed to shift in its position. Fig. 4 shows the carbidic and elemental carbon amount and the binding energy shift of the carbide fraction as a function of the deposited layer thickness. The BE shift of the carbide peak is observed on both Ni surfaces. Within the first monolayer the binding energy is close to the bulk value at $283.45 \mathrm{eV}$, immediately after additional $\mathrm{C}$ deposition this value decreases $(283.30 \mathrm{eV})$ and reaches the bulk value $(283.55 \pm 0.05 \mathrm{eV}$ in average) again after $\sim 4 \mathrm{ML}$. The Ni $2 p_{3 / 2}$ peak shows a small change in the position towards higher binding energy $(\Delta \mathrm{BE}=0.2 \mathrm{eV})$ after submonolayer deposition. A continuous shift like in the $\mathrm{C} 1 s$ peak region is not observed. Within the Ni $2 p$ signal we cannot identify an additional component, only the peak position shifts slightly. Therefore, the substrate signal is not further analyzed. The valence band region exhibits a similar peak shift $(\Delta \mathrm{BE}=0.2 \mathrm{eV})$ as the Ni $2 p$ region. A comparison of core-level binding energies measured in our work with values given in the literature is listed in Table II.

\section{B. Thermally induced processes}

In order to investigate possible reaction or diffusion processes at elevated temperatures, the carbon films are annealed in steps of 50 or $100 \mathrm{~K}$ between room temperature and $970 \mathrm{~K}$. The sample is kept at each temperature for 30 minutes. The XPS measurements are performed after cooling down to room temperature. Parameters which can influence possible reaction and diffusion processes are the carbon layer thickness, annealing time and $\mathrm{Ni}$ surface, respectively. The carbon diffusion is analyzed by observing the carbon layer thickness. To compare the diffusion from surface to the bulk, carbon films of similar thicknesses are deposited on the $\mathrm{Ni}(111)$ and

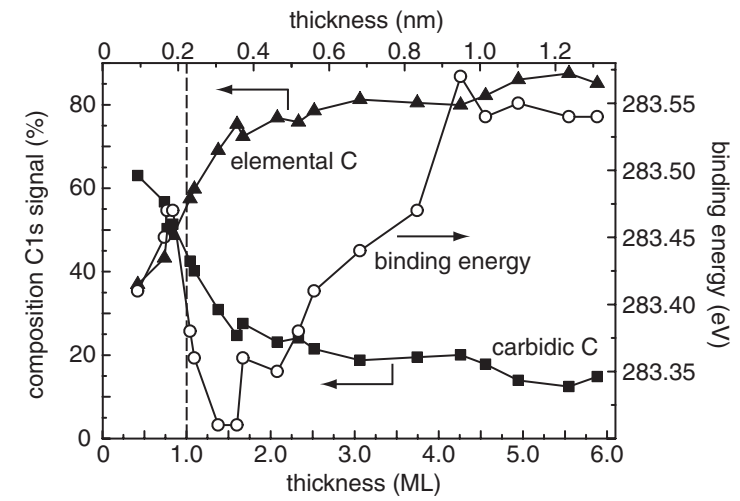

FIG. 4: Elemental ( $\boldsymbol{\Delta})$ and carbidic C intensity fractions ( $\mathbf{\square})$, compared with the binding energy shift $(\mathrm{O})$ of the carbidic component from the sub-monolayer region up to $6 \mathrm{ML}$ after carbon deposition on $\mathrm{Ni}(111)$ and $\mathrm{Ni}(100)$. The carbide peak binding energy is referred to the peak position of graphitic $\mathrm{C}$ at $284.2 \mathrm{eV}$. The carbide $\mathrm{BE}$ has a minimum at a $\mathrm{C}$ layer thickness of $1.5 \mathrm{ML}$ and reaches the bulk value at $4 \mathrm{ML}$ coverage.

$\mathrm{Ni}(100)$ surfaces. Fig. 5 shows these two comparable carbon layers (1.8 and $1.9 \mathrm{~nm})$ on $\mathrm{Ni}(100)$ and $\mathrm{Ni}(111)$. In addition we show the thermal evolution of a thin carbon film on $\mathrm{Ni}(111)(0.4 \mathrm{~nm})$ and one further carbon layer on $\mathrm{Ni}(100)(1.5 \mathrm{~nm})$. The carbon diffusion sets in at $650 \mathrm{~K}$ on the more open surface structure (100) and at $750 \mathrm{~K}$ on $\mathrm{Ni}(111)$, indicated by the dashed lines in Fig. 5 . The carbon is almost completely lost into the bulk within a temperature window of $150 \mathrm{~K}$ above the onset of surfaceto-bulk diffusion. Compared to other metals, on $\mathrm{Ni}(111)$ and $\mathrm{Ni}(100)$ a changed decrease rate of the carbon signal is observed before the carbon is fully lost into the bulk. This small step in the layer thickness is observed in particular for layers above several monolayers, and leads to a less strong decrease for thin layers (as shown for the $0.4 \mathrm{~nm}$ film on $\mathrm{Ni}(111)$ ). This thin carbon layer was annealed for only 20 minutes at each temperature step. A pronounced carbon diffusion at $750 \mathrm{~K}$ is not observed. After the carbon diffusion a residual carbon layer thickness of less than 1 monolayer is observed on both $\mathrm{Ni}$ surfaces. At $970 \mathrm{~K}$ the $\mathrm{C} 1 s$ intensity is almost completely lost on both Ni surfaces. For the layer thickness estimation we use inelastic mean free paths for $\mathrm{C} 1 \mathrm{~s}$ and $\mathrm{Ni} 2 \mathrm{p}$ photoelectrons passing a graphite layer. During the thermal treatment the carbon layer is modified and the inelastic mean free path could change due to altered layer densities and composition (e.g. $\mathrm{Ni}_{3} \mathrm{C}$ formation). A pure carbide layer would change the inelastic mean free paths by a factor of 1.6 applying the Seah-Denchequation for inorganic compounds. However, as we will show in the next section, the carbide intensity is small and the elemental carbon dominates the $\mathrm{C} 1 s$ signal up to high temperatures.

As described above in section IV A, the inelastic background in the spectra is evaluated on the high-BE side of the Ni $3 p$ signal for determination of the growth mode af- 


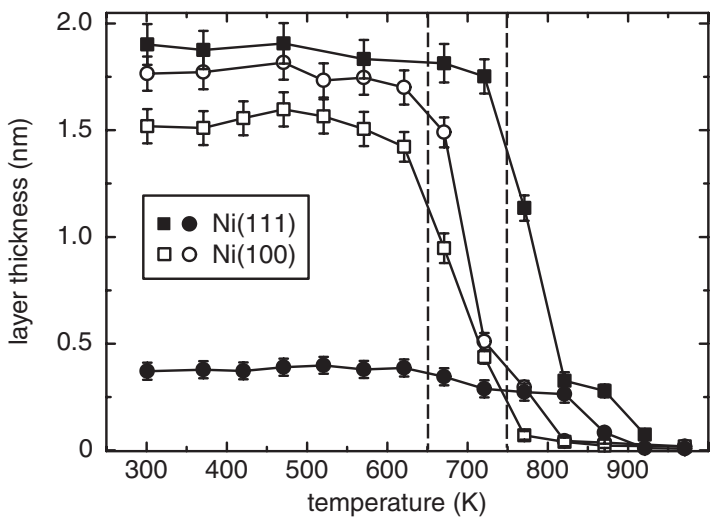

FIG. 5: Thermal behavior of carbon films with different initial layer thicknesses on $\mathrm{Ni}(100)$ and $\mathrm{Ni}(111)$. The $\mathrm{Ni}(100)$ surface (open symbols) shows an onset temperature of carbon diffusion at $\sim 650 \mathrm{~K}$, the $\mathrm{Ni}(111)$ surface (filled symbols) at $\sim 750 \mathrm{~K}$ (marked by dashed lines). The error bars represent statistical errors from both measured intensities.

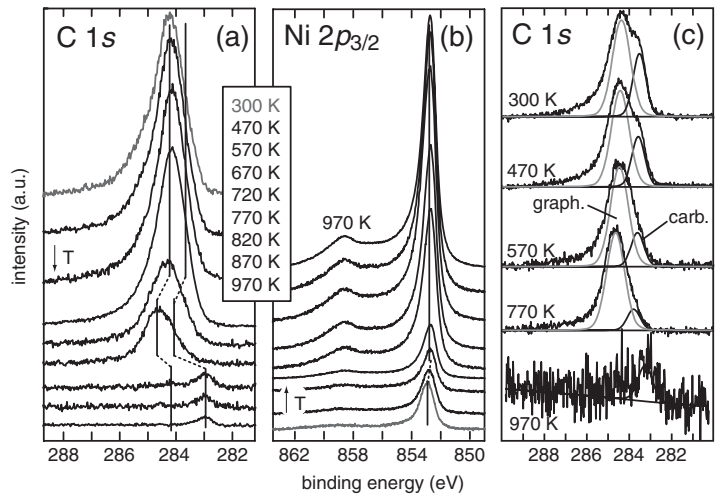

FIG. 6: $\mathrm{C} 1 s$ and $\mathrm{Ni} 2 p_{3 / 2}$ signal regions from a $1.8 \mathrm{~nm} \mathrm{C}$ film on $\mathrm{Ni}(100)$ (a and b), plotted with increasing annealing temperatures (see arrow directions). In panel (c) the $\mathrm{C} 1 s$ signals for a $0.4 \mathrm{~nm}$ thin carbon film on $\mathrm{Ni}(111)$ are shown. The carbide decomposition reaction is visible as a loss of the carbide intensity. The Ni $2 p$ peak (b) shifts with beginning carbide decomposition from the carbide position towards the metal value $(\Delta \mathrm{BE}=-0.2 \mathrm{eV})$. With incipient carbon diffusion a total $\mathrm{C} 1 s$ peak shift towards higher values is observed (a, c). The peak positions of carbidic and graphitic carbon are labeled. The residual carbide signal observed at temperatures above $850 \mathrm{~K}$ shifts to lower values, compared to the respective peaks in the signals at lower annealing temperatures.

ter room temperature deposition (see Fig. 1). Comparing the spectra in this $\mathrm{BE}$ region with increasing annealing temperature, island formation during the annealing experiments can be excluded. Therefore, the carbon layer thickness determination by assuming a model which is based on a layer growth mode is justified.

In Fig. 6 the binding energy regions of the $\mathrm{C} 1 s$ and substrate signals for a $1.8 \mathrm{~nm}$ thick film on $\mathrm{Ni}(100)$ (panel $\mathrm{a}$ and $\mathrm{b}$ ) are shown. In panel (c) the $\mathrm{C} 1 s$ signals for the $0.4 \mathrm{~nm}$ carbon film on $\mathrm{Ni}(111)$ are plotted, together with the fit results for graphitic and carbidic carbon. Since the disordered fraction is small for very thin films, this peak is omitted for clarity. Different temperature regions and signal shifts due to reactions are observed and analyzed in detail in the following. The results of the quantitative analysis of the $\mathrm{C} 1 s$ signals with increasing temperature by applying the MultiPak peak fitting routine is shown in Fig. 7. We now focus on a carbon film $(1.8 \mathrm{~nm}$, Fig. 5, 6a, b) deposited on $\mathrm{Ni}(100)$ for which the changes of the carbon chemical states are plotted in Fig. 7a. The fraction of carbidic carbon shows an initial decrease with increasing annealing temperatures up to $\sim 500 \mathrm{~K}$ while the total carbon amount at the surface is unchanged. The carbide intensity starts to increase from this lower intensity level for temperatures above the minimum around $600 \mathrm{~K}$. At $650 \mathrm{~K}$ the carbon diffusion sets in, accompanied by an increase of the carbide fraction. The carbon is almost completely lost from the surface (accessible by XPS) into the bulk within a temperature window of $150 \mathrm{~K}$. The C 1 s signal shows only carbide intensity above $870 \mathrm{~K}$, the elemental carbon vanishes completely. For comparison, the $1.9 \mathrm{~nm}$ thick film on $\mathrm{Ni}(111)$, shown in Fig. 7b, exhibits only a small variation in the carbide amount, still going through a minimum in the temperature range of 400 570 K. In a similar experiment on $\mathrm{Ni}(111)$, starting however with a thinner carbon layer of $0.4 \mathrm{~nm}$ (Fig. 6c, 7b), also a minimum in the same temperature range is observed. This carbide decomposition is visible as a loss of carbide intensity whereas the total $\mathrm{C} 1 s$ signal intensity is almost constant. Compared to $\mathrm{Ni}(100)$, the diffusion sets in at $750 \mathrm{~K}$. The carbon is lost into the bulk at a temperature above $920 \mathrm{~K}$. The $\mathrm{C} 1 s$ signal exhibits elemental as well as carbidic carbon still at $920 \mathrm{~K}$. Also the thin carbon film $(0.4 \mathrm{~nm})$ shows an incomplete reaction, visible as elemental and carbidic $\mathrm{C} 1 s$ signal components at $920 \mathrm{~K}$. At $970 \mathrm{~K}$ again only carbidic carbon is observed for the thin film (see Fig. 6c and 7b).

The carbide decomposition (temperature region where the carbide fraction passes through a minimum) is visible in the substrate signal (Fig. 6b). Above RT, the Ni $2 p$ signal shows a binding energy shift towards the metal value $(\Delta \mathrm{BE}=-0.2 \mathrm{eV})$. The $\mathrm{C} 1 s$ binding energy region shows no overall shift during the carbide decomposition reaction (470-670 K) (panels a and c). Accompanied with the onset of carbon diffusion at $750 \mathrm{~K}$ the $\mathrm{C} 1 s$ signal shifts towards higher binding energy values while the substrate signal position is not modified. The graphite peak position (labeled 'graph.' in Fig. 6c) is at $284.6 \mathrm{eV}$ $(\triangle \mathrm{BE}=0.4 \mathrm{eV})$ and the carbide intensity (labeled 'carb.' in Fig. 6c) is determined at $283.9 \mathrm{eV}(\Delta \mathrm{BE}=0.3 \mathrm{eV})$. After the majority of carbon is lost into the bulk (above $870 \mathrm{~K}$ ), only a small $\mathrm{C} 1 s$ peak remains at the carbide peak position. The binding energy of $283.0 \mathrm{eV}$ for this peak is comparable (although somewhat smaller) to the low coverage value given in Fig. 4. An identical behavior is observed for carbon films on $\mathrm{Ni}(111)$. The substrate signal shifts towards the metal value with beginning carbide decomposition (carbide minimum region) and stays constant up to $970 \mathrm{~K}$. In the C $1 s$ signal a shift towards 

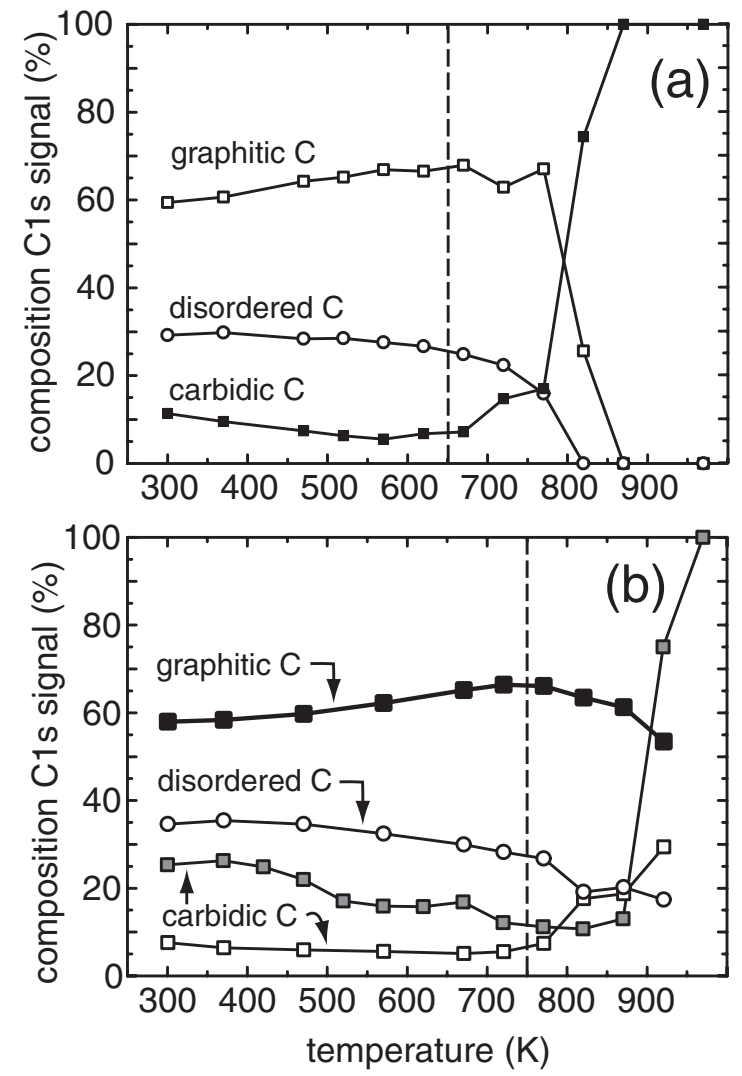

FIG. 7: Changes in the components of the $\mathrm{C} 1 s$ signal with annealing temperature for carbon films on $\mathrm{Ni}(100)$ (a) and on $\mathrm{Ni}(111)$ (b). The initially deposited carbon layer on $\mathrm{Ni}(100)$ is $1.8 \mathrm{~nm}$. On $\mathrm{Ni}(111)$ the initial carbon layer thickness amounts to $1.9 \mathrm{~nm}$. In addition, the thermal evolution of the carbidic carbon for a $0.4 \mathrm{~nm}$ thin film is shown in (b) by the grey symbols). The temperatures of incipient carbon diffusion from Fig. 5 are marked by dashed lines. The carbon film on $\mathrm{Ni}(100)$ shows a pronounced minimum in the carbide component ( $\boldsymbol{\square})$. For the $1.9 \mathrm{~nm}$ film on $\mathrm{Ni}(111)$ only a small minimum in the carbide fraction is visible, whereas the $0.4 \mathrm{~nm}$ thin film clearly shows the carbide decomposition reaction. The graphitic carbon fraction $(\square)$ increases due to rearrangement of disordered (O) into ordered C. Additional carbide is formed upon incipient carbon diffusion. Above $850 \mathrm{~K}$ the remaining carbon signal on $\mathrm{Ni}(100)$ shows only carbide intensity, whereas on $\mathrm{Ni}(111)$ at $920 \mathrm{~K}$ the carbide formation is still incomplete.

higher values with the onset of carbon diffusion is measured. The residual carbide intensity after the annealing steps at $920 \mathrm{~K}$ is again observed at lower $\mathrm{BE}$ values compared to the bulk carbide position (Fig. 6c).

On both nickel surfaces an ordering reaction within the elemental carbon is observed which leads to an increase in graphitic carbon (peak at a BE of $284.2 \mathrm{eV}$ ), while the disordered fraction decreases (peak intensity at $285.1 \mathrm{eV}$ ). The ratio of disordered and ordered graphitic $\mathrm{C}$ decreases from 0.6 at maximum after room temperature deposition to 0.2 at minimum, before the carbon is lost into the bulk. This ordering reaction is also observed in annealing experiments of carbon films on $\mathrm{Au}, \mathrm{W}, \mathrm{Si}$,
$\mathrm{Ti}, \mathrm{W}$, and in case of HOPG (highly oriented pyrolytic graphite) after ion bombardment [22-25]. This is visible in Fig. 7 for both Ni surfaces, in particular in the temperature regime from $\mathrm{RT}$ to the onset of carbon diffusion from the surface into the bulk (650 K on $\mathrm{Ni}(100)$, $750 \mathrm{~K}$ on $\mathrm{Ni}(111))$.

\section{DISCUSSION}

The first part of this section discusses the information gained on surface structure and layer growth modes, which is deduced from the observed binding energies and their respective shifts during the deposition of carbon on the nickel surfaces. Bäumer et al. deposited $\mathrm{Ni}$ on the basal plane of graphite at low $(90 \mathrm{~K})$ and room temperature $(300 \mathrm{~K})$ and characterized the system with LEED and XPS [38]. The authors report cluster growth at these temperatures. In our work the inverse system (carbon on $\mathrm{Ni}$ ) at room temperature is investigated. An analysis of substrate and layer signals with increasing carbon layer thicknesses indicate initially a layer growth mode. In particular, an island growth mode is excluded from a comparison of the evolution of the inelastic background with increasing layer thickness. As the simulated spectra show, the island growth mode would appear as a distinct increase of the inelastic background while a layer growth mode leads to a smooth background beside the XPS line. For thicker carbon films $(>1.3 \mathrm{~nm})$ our analysis of survey spectra an initial layer-by-layer growth, followed by island growth, is concluded (see Fig. 1). The inelastic background beside the Ni $3 p$ signal increases only slightly with increasing layer thickness. However, for detailed and more direct studies of the growth mode of elemental carbon deposited on nickel other UHV techniques like STM are required.

XPS measurements after room temperature deposition with increasing carbon layer thicknesses show a clearly visible shift in the carbide binding energy. Two different characteristics are identified. In the sub-monolayer region the carbide peak is close to the bulk $\mathrm{BE}$ value at $283.45 \mathrm{eV}$, followed by a decrease in BE. The carbide peak position is determined at $283.3 \mathrm{eV}$ at minimum for a layer thickness of 1.5 ML. Above this coverage the carbide peak shifts again continuously towards higher values, until the bulk value for $\mathrm{Ni}_{3} \mathrm{C}$ of $283.50-283.55 \mathrm{eV}$ is reached at $4 \mathrm{ML}$. The BE shift detected at sub-monolayer coverages can be related to the surface reconstruction ('clock reconstruction') described in literature for this coverage regime $[9,10,12]$. This surface reconstruction is observed for carbon films both on $\mathrm{Ni}(111)$ and $\mathrm{Ni}(100)$ between a coverage of 0.2 and 0.6 ML. Carbon deposition (by hydrocarbon decomposition) above this coverage leads to graphite formation in these studies. Due to the carbide signal position and the carbide amount of less than $100 \%$ in that coverage region we assume a similar surface reconstruction in our case after carbon deposition from the vapor phase. However, in all previous investigations of the 
$\mathrm{C} / \mathrm{Ni}$ system by other groups carbon was never deposited elemental from the vapor phase and with substrates at RT. The interpretation of a surface reconstruction is deduced in our case from the shift of the carbide peaks. The continuous shift from $283.3 \mathrm{eV}$ to again higher BEs (283.5 $-283.55 \mathrm{eV}$ ) between 1.5 ML and $4 \mathrm{ML}$ is explained by a size effect, as discussed in [39] (the author gives there an extensive survey on core-level shifts). The carbide peak position is then affected by the increasing graphite matrix. Based on the interpretation of the BE shift due to this size effect, this BE shift can be quantitatively estimated using the thermodynamic approach described by Mårtensson et al. [40]. In this model the BE shift is calculated by the ' $Z+1$ ' approach. This approach is also known as the equivalent-core-approximation (ECA) and is used for the determination of surface core level shifts and binding energy shifts in binary compounds like alloys (see also [39]). In this approach the overall enthalpy can be written as a sum of the enthalpies of all reaction sequences. This is also known in literature as the 'Born-Haber cycle', which can be written in terms of the enthalpy of solution $\left(\Delta H_{S o l}\right)$ for the binary system $Z ; Z+1$ (equation 6).

$$
\Delta E_{B}=\Delta H_{\text {Sol }}^{Z \rightarrow Z+1}+\Delta H_{\text {Sol }}^{Z+1 \rightarrow Z}
$$

This equation has to be improved for binary compounds $\left(\mathrm{A}_{x} \mathrm{~B}_{y}\right)$ where $\mathrm{A}$ is equivalent to $Z$ and $\mathrm{A}+1$ represents $Z+1$, respectively, and $\mathrm{B}$ is the matrix $[40,41]$. The $\mathrm{BE}$ shift $\left(\Delta E_{B}\right)$ is then correlated to the energies of solution $(E(\mathrm{~A} ; \mathrm{B}), E(\mathrm{~A}+1 ; \mathrm{B}), E(\mathrm{~A}+1, \mathrm{~A}))$. The essential thermodynamic values are determined using the semi-empirical equation given in [42]. For this equation physical values like atomic volume and work function as well as empirical scaling values are essential. It should be noted, that the semi-empirical equation is only valid for a concentration of $5 \% \mathrm{~A}$ in $\mathrm{B}$ at maximum. Cluster size effects represent this concentration limit and the determined values can be used for the estimation of a $\mathrm{BE}$ shift applying the ' $Z+1$ ' approach as given in literature. Applying this ' $Z+1$ ' approach to our system we expect a $\mathrm{BE}$ shift for the carbide peak position in the $\mathrm{C} 1 s$ signal of $-0.61 \mathrm{eV}$, compared to the experimentally determined value of $-0.89 \mathrm{eV}(283.3 \mathrm{eV})$ in maximum in the $1-2 \mathrm{ML}$ coverage region. For the Ni $2 p$ signal a binding energy shift of $+0.8 \mathrm{eV}$ is expected from this model. We observe a shift of $+0.2 \mathrm{eV}$ in maximum in our experiments. A continuous BE shift with increasing carbon layer thickness is not observed. For comparison, Gibbs et al. measured a BE shift of $+0.9 \mathrm{eV}$ for the Ni $2 p$ signal after Ni implantation in carbon [36], which is within the conditions of the ' $Z+1$ ' approach (low concentration of $\mathrm{Ni}$ in $\mathrm{C})$. These experiments and model calculations, however, are not directly comparable to our measurements due to different concentrations of $\mathrm{Ni}$ and $\mathrm{C}$. The given model values and measurements by Gibbs et al. represent the 'low concentration' range of $\mathrm{Ni}$ in $\mathrm{C}$, while our measurements are performed at the reverse concentration limit (large amount of $\mathrm{Ni}$ ). An investigation of core level shifts on binary metal systems which form random alloys $\left(\mathrm{A}_{x} \mathrm{~B}_{y}\right)$ shows a linear dependence on the stoichiometric ratio of $\mathrm{A}$ and B [41]. Therefore, the core level shift of a binary system $\left(\mathrm{A}_{x} \mathrm{~B}_{y}\right)$ can be estimated by an evaluation of the 'low concentration' value (5\% $\mathrm{A}$ in $\mathrm{B}$ and vice versa) applying the ' $Z+1$ ' approach. This value represents the $\mathrm{BE}$ shift for element $\mathrm{A}$ and $\mathrm{B}$, respectively for the binary system in maximum. The second point is a core level shift of $\triangle \mathrm{BE}=0 \mathrm{eV}$ representing the bulk values for A $(100 \% \mathrm{~A})$ and B $(100 \% \mathrm{~B})$. Under assumption of a linear dependence from the 'low concentration' to the '100 \%' side the core level shift of $\mathrm{A}_{x} \mathrm{~B}_{y}$ can be determined for the respective $x$ and $y$ values. The expected $\mathrm{BE}$ values according to such a linear interpolation for $\mathrm{Ni}_{3} \mathrm{C}(25 \% \mathrm{~B}$ in A) are: $+0.2 \mathrm{eV}$ for $\mathrm{Ni} 2 p$ and $-0.5 \mathrm{eV}$ for carbide in $\mathrm{C} 1 s$. These values are in good agreement with our experimentally determined BE shifts of $+0.2 \mathrm{eV}$ $(\mathrm{Ni} 2 p)$ and $-0.7 \mathrm{eV}$ (carbidic C $1 s$ ). To summarize these observations, we assume a surface reconstruction in the carbon sub-monolayer region, followed by a size effect between 1.5 ML and 4 ML. The additional carbon deposition above $1.5 \mathrm{ML}$ is not leading to a further surface reconstruction and the carbide particles are embedded and finally covered by a graphite matrix with a contribution of defects in the graphite lattice.

The second part of the discussion is devoted to reaction and diffusion processes of elemental carbon on nickel, particularly taking into account the endothermic nature of $\mathrm{Ni}_{3} \mathrm{C}$. In the quantitative XPS analysis of the $\mathrm{C} 1 \mathrm{~s}$ signal composition we find a maximum carbide amount while the first carbon monolayer is deposited. $65 \%$ of the $\mathrm{C} 1 s$ signal intensity corresponds to the carbide. Although the formation reaction of $\mathrm{Ni}_{3} \mathrm{C}$ is endothermic, the carbide is detected after depositing carbon from the vapor phase on nickel at room temperature. We deposit carbon films on different materials (W, Be, Ti and $\mathrm{Si}$ ) with respect to the thermodynamic properties of their carbides. On these substrates the corresponding carbides show exothermic carbide formation reactions. Accordingly, the carbon films exhibit a larger carbide fraction after room temperature deposition compared to Ni. In the case of carbon films on Be, for example, we find an increase in carbide intensity while depositing carbon layers up to 3 ML [22].

In [43] we give a survey about all binary systems measured in our group by now. A comparison of carbon films on various substrates $(\mathrm{Be}, \mathrm{Si}, \mathrm{W}, \mathrm{Ti}$ and $\mathrm{Ni}$ ) shows a dependence of the thermal behavior on thermodynamic properties (diffusion and carbide formation processes). The onset temperature of carbon diffusion on those substrates which show carbides with comparable carbide structures (intercalation compounds) corresponds to the tendency of the respective activation barriers for carbon diffusion in the bulk metals. These values are given in literature [44]. $\mathrm{Ni}(100)$ shows the lowest onset temperature, followed by $\mathrm{Ti}(1.3 \mathrm{eV}), \mathrm{Ni}(111)$ and $\mathrm{W}(1.8 \mathrm{eV})$. The activation barrier for carbon diffusion in bulk $\mathrm{Ni}$ is $1.5 \mathrm{eV}$ [44]. The difference between $\mathrm{Ni}(100)$ and $\mathrm{Ni}(111)$ 
observed in this work (Fig. 5) is explained by the more open surface structure of $\mathrm{Ni}(100)$. For a detailed explanation of the reaction and diffusion kinetics we refer to [45]. Another aspect of interest is the carbide formation reaction and their thermodynamic properties. The carbides of both $\mathrm{Ti}$ and $\mathrm{W}$ are formed in an exothermic formation $\left(\Delta G_{f}^{0}<0\right)$ reaction, whereas the respective $\mathrm{Ni}$ carbide is formed in an endothermic reaction $\left(\Delta G_{f}^{0}>\right.$ 0 ). Carbon films on $\mathrm{Ti}$ and $\mathrm{W}$ show a noticeable carbide formation after annealing experiments at higher temperatures, which agrees with the exothermic reaction behavior. On Ni, however, we cannot observe a clearly visible increase in carbide intensity (Fig. 7). With the onset of carbon diffusion ( $T_{\text {Diff }}$ is given as a line in Fig. 7 ) the carbide amount increases only barely. Another difference to the carbides formed in an exothermic reaction is the temperature window in which a minimum in the carbide fraction is observed. The decrease of initially present carbide is attributed to the metastable character of $\mathrm{Ni}_{3} \mathrm{C}$. With increasing annealing temperature the carbide formed upon initial C deposition at RT decomposes, leading to an increasing intensity of elemental carbon. The carbide decomposition was already observed by Levenson et al. [17-19]. They reported a beginning decrease in carbide amount at $420 \mathrm{~K}$ and a complete decomposition at $670 \mathrm{~K}$. However, we observe carbide intensity up to $970 \mathrm{~K}$. Levenson et al. investigated $\mathrm{Ni}$ implanted into carbon substrates. Therefore, small amounts of remaining carbide might be obscured by the dominating signal of the elemental carbon in the substrate. Since in our measurements the $\mathrm{C} 1 s$ signal intensity is constant in that temperature region, the carbide decomposition is explained by a surface process and a reconstruction, respectively.

We now focus on the BE shifts of the carbon core-level peaks. During the peak fits we set the peak separation of graphitic and disordered graphitic carbon within the C $1 s$ signal constant. Only the carbidic carbon peak is allowed to shift in its position. Firstly we will focus on the total C $1 s$ signal, followed by the discussion of the detailed deconvolution. Independent on the surface structure $(\mathrm{Ni}(111)$ and $\mathrm{Ni}(100))$ the total $\mathrm{C} 1 s$ signal shifts towards higher values while carbon diffusion sets in. In contrast, the valence band and Ni $2 p$ regions shift to lower BEs already at lower temperatures, with the onset of carbide decomposition, and show no further change in peak position during the following thermal treatments. Therefore, the shifts of Ni $2 p$, valence band and $\mathrm{C} 1 s$ regions cannot be explained by changed experimental properties. In that case, the regions would show a position change at the same temperature and, moreover, in the same direction. The Ni $2 p$ as well as the valence band region shift due to the carbide decomposition and the peak energies then correspond with the respective metal values. The changes in the $\mathrm{C} 1 s$ signal, however, occur while the carbon is lost into the bulk and after carbon diffusion. In that temperature region the carbon migrates into the bulk and the Ni surface and bulk atoms have to rearrange for carbide formation and carbon diffusion. Consequently, the BE shifts occurring upon carbon diffusion are attributed to a rearrangement of surface atoms. In addition, there is no evidence for other carbon species than elemental and carbidic carbon. Since direct measurements of the surface atoms (like STM) of our reactive binary system are not done by now we conclude this rearrangement of surface atoms from the already described BE shift for carbon films after room temperature deposition ('clock reconstruction'). The carbide peak position of the residual $\mathrm{C} 1 s$ signal is at lower values compared to the $\mathrm{Ni}_{3} \mathrm{C}$ bulk position. This observation is due to the already described size effect (see $\mathrm{C}$ deposition on $\mathrm{Ni}$ at RT) and isolated carbide particles. Continuing with the composition of the $\mathrm{C} 1 s$ signal. Independent from the substrate $(\mathrm{C}$ on $\mathrm{Be}, \mathrm{Si}, \mathrm{W}, \mathrm{Ti}$ and $\mathrm{Ni}$ ) we find elemental carbon with a similar ratio of graphitic and disordered graphitic carbon. Upon continuing carbon deposition the disordered carbon fraction increases with carbon layer thickness up to a maximum ratio of disordered to graphitic $\mathrm{C}$ of 0.6 . The disordered fraction is comparable to 'non-perfect' $\mathrm{sp}^{2} \mathrm{C}$ and the decrease of that intensity during annealing is ascribed to a rearrangement into ordered $\left(\mathrm{sp}^{2}\right)$ graphite. In earlier experiments we deposited carbon films on gold, which is an inert substrate with respect to both carbide formation and carbon bulk diffusion. Therefore, carbon diffusion or any other reaction can be excluded. The deposited carbon films show a clearly visible ordering after thermal treatment. This ordering reaction in the deposited carbon films also occurs on reactive substrates during annealing experiments $([22-25])$. The resulting chemical state of the carbon after the onset of diffusion into the Ni bulk at temperatures up to $970 \mathrm{~K}$ depends on the surface orientation. After deposition of comparable layer thicknesses and equal annealing times we find elemental as well as carbidic $\mathrm{C}$ on $\mathrm{Ni}(111)$ and only carbidic $\mathrm{C}$ on $\mathrm{Ni}(100)$. This again is due to the more open surface structure of $\mathrm{Ni}(100)$ and the onset of carbon diffusion at lower temperatures, compared to $\mathrm{Ni}(111)$. The detection of carbide intensity even after the onset of carbon diffusion and the decreasing $\mathrm{C} 1 \mathrm{~s}$ signal is explained by carbon segregation. The solubility of carbon in $\mathrm{Ni}$ is small, increases with temperature and amounts to $2.7 \%$ in $\mathrm{Ni}$ at $1600 \mathrm{~K}[46,47]$. The $\mathrm{C} 1 s$ signal intensity during the annealing procedure at $970 \mathrm{~K}$ is almost completely lost due to the higher solubility compared to $300 \mathrm{~K}$. During cooling down to room temperature, however, the $\mathrm{C} 1 s$ signal intensity appears again due to carbon atoms migrating back to the $\mathrm{Ni}$ surface. Carbon segregation on $\mathrm{Ni}$ was also observed by $[7,8]$ and was actually applied for carbon enrichment experiments described in [1].

\section{SUMMARY}

This paper comprehensively describes for the first time the interaction of carbon deposited elementally at room 
temperature on nickel surfaces, followed by annealing steps up to $970 \mathrm{~K}$. To this, carbon films of different thicknesses from sub- to several monolayers are deposited on $\mathrm{Ni}(100)$ and $\mathrm{Ni}(111)$. The carbon-metal reaction and diffusion processes at RT and at elevated temperatures are compared with other binary $\mathrm{C} /$ metal systems. $\mathrm{Ni}_{3} \mathrm{C}$, although being formed in an endothermic reaction, is detected after room temperature deposition of carbon. An analysis of the $\mathrm{C} 1 \mathrm{~s}$ signals shows carbide intensity restricted to the film-substrate interface. The initially formed carbide decomposes during annealing up to $570 \mathrm{~K}$ (temperature window of minimum carbide intensity), demonstrating the metastable character of $\mathrm{Ni}_{3} \mathrm{C}$. After heating to higher temperatures, carbide intensity is observed, accompanied by carbon diffusion into the bulk. The onset temperatures of both carbon diffusion from surface into bulk and carbide formation depend on the surface structure. $\mathrm{Ni}(100)$ shows an onset around $650 \mathrm{~K}$, whereas the diffusion and reaction on $\mathrm{Ni}(111)$ set in at $750 \mathrm{~K}$. The different characteristics in BE shift for the $\mathrm{C} 1 s$ signal are explained by surface reconstruction in the carbon sub-monolayer region and carbon diffusion, respectively. The carbide peak position is detected close to the carbide bulk value while elemental carbon is deposited in the sub-monolayer region. This observation is explained by the 'clock reconstruction' of the Ni surface, described in the literature. Deposition of elemental carbon from 1.5 ML up to $4 \mathrm{ML}$ leads to a continuous carbide peak shift from a distinct $\mathrm{BE}$ minimum to the carbide bulk value. The $\mathrm{BE}$ shift in this coverage region is explained by a cluster size effect. The $\mathrm{C} 1 s$ signal position shifts again during annealing experiments. The first $\mathrm{BE}$ shift to higher values is measured when the carbon diffusion is observed, followed by a second BE shift to lower values when the carbon atoms segregate back to the surface. While the first BE shift is explained by the diffusion process where the $\mathrm{Ni}$ surface and bulk atoms have to rearrange for carbon diffusion, the additional $\mathrm{BE}$ shift after the final thermal treatment is explained by the cluster size effect.
[1] M. Eizenberg, J.M. Blakely, J. Chem. Phys. 71 (1979) 3467.

[2] M. Eizenberg, J.M. Blakely, Surf. Sci. 82 (1979) 228.

[3] J.G. McCarthy, R J. Madix, Surf. Sci. 54 (1979) 121.

[4] F.C. Schouten, E. Te Brake, O.L.J. Gijzeman, G.A. Bootsma, Surf. Sci. 74 (1978) 1.

[5] E.O. F. Zdansky, A. Nilsson, N. Mårtensson, Surf. Sci. 310 (1994) L583.

[6] R. Rosei, M. De Crescebzi, F. Sette, C. Quereima, A. Savoia, P. Perfetti, Phys. Rev. B 28 (1983) 1161.

[7] C.M. Whelan, R. Neubauer, D. Borgmann, R. Denecke, H.-P. Steinrück, J. Chem. Phys. 115 (2001) 8133.

[8] R. Neubauer, C.M. Whelan, R. Denecke, H.-P. Steinrück, Surf. Sci. 507-510 (2002) 832.

[9] C. Klink, I. Stensgaard, F. Besenbacher, E. Lægsgaard, Surf. Sci. 342 (1995) 250.

[10] C. Klink, L. Olesen, F. Besenbacher, I. Stensgaard, E. Lægsgaard, N.D. Lang, Phys. Rev. Lett. 71 (1993) 4350.

[11] J.H. Onuferko, D.P. Woodruff, B.W. Holland, Surf. Sci. 87 (1979) 357.

[12] K.C. Prince, M. Surman, T. Lindner, A.M. Bradshaw, Solid State Commun. 59 (1986) 71.

[13] R. Terborg, J.T. Hoeft, M. Polcik, R. Lindsay, O. Schaff, A.M. Bradshaw, R.L. Toomes, N.A. Booth, D.P. Woodruff, E. Rotenberg, J. Denlinger, Surf. Sci. 446 (2000) 301.

[14] H. Nakano, J. Nakamura, Surf. Sci. 482-485 (2001) 341.

[15] H. Nakano, S. Kawakami, T. Fujitani, J. Nakamura, Surf. Sci. 454-456 (2000) 295.

[16] H. Nakano, J. Ogawa, J. Nakamura, Surf. Sci. 514 (2002) 256.

[17] S. Sinharoy, M.A. Smith, L.L. Levenson, Surf. Sci. 72 (1978) 710.

[18] S. Sinharoy, L.L. Levenson, Thin Solid Films 53 (1978) 31.

[19] M.A. Smith, S. Sinharoy, L.L. Levenson, J. Vac. Sci. Technol. A 16 (1979) 462.
[20] W.F. Egelhoff, Jr., G.G. Tibbetts, Solid State Comm. 29 (1978) 53.

[21] W.F. Egelhoff, Jr., G.G. Tibbetts, Phys. Rev. B 19 (1979) 5028.

[22] P. Goldstrass, K.U. Klages, Ch. Linsmeier, J. Nucl. Mat. 290-293 (2001) 76.

[23] J. Luthin, Ch. Linsmeier, Surf. Sci. 454-456 (2000) 78.

[24] Ch. Linsmeier, J. Luthin, P. Goldstrass, J. Nucl. Mat. 290-293 (2001) 25.

[25] J. Luthin, Ch. Linsmeier, Physica Scripta T91 (2001) 134

[26] P. Reinke, P. Oelhafen, Surf. Sci. 468 (2000) 203.

[27] I. Barin, Thermochemical Data of Pure Substances, V.1\&2, VCH, Weinheim, 3rd ed., Weinheim (1995).

[28] M.P. Seah, I.S. Gilmore, G. Beamson, Surf. Interface Anal. 26 (1998) 642.

[29] MultiPak Ver. 8.2B, Physical Electronics (2006). This code uses a sum of Gauss and Lorentz functions to approximate the Voigt function.

[30] M.P. Seah, W.A. Dench, Surf. Interf. Anal. 1 (1979) 2.

[31] B. Lesiak, A. Jablonski, Z. Prussak, P. Mrozek, Surf. Sci. 223 (1989) 213.

[32] J.F. Moulder, W.F. Stickle, P.E. Sobol, K.E. Bomben, Handbook of X-ray photoelectron spectroscopy, Ed. J. Chastain, Perkin Elmer Corp. Eden Prairie (1992).

[33] S. Tougaard, QUASES background analysis of XPS / AES., part 1 and 2, 1994 - 1999 QUASES - Tougaard APS.

[34] S. Tougaard, J. Vac. Sci. Technol. A 14 (1996) 1415.

[35] S. Tougaard, Surf. Interface Anal. 26 (1998) 249.

[36] R.A. Gibbs, N. Winograd, V.Y. Young, J. Chem. Phys. 72 (1980) 4799.

[37] M.G. Mason, Phys. Rev. B 27 (1983) 748.

[38] M. Bäumer, J. Libuda, H.J. Freund, Surf. Sci. 327 (1995) 321.

[39] W.F. Egelhoff, Jr., Surf. Sci. Reports 6 (1987) 253.

[40] P. Steiner, S. Hüfner, N. Mårtensson, B. Johansson, Solid 
State Commun. 37 (1981) 73.

[41] N. Mårtensson, R. Nyholm, H. Calén, J. Hedman, B. Johansson, Phys. Rev. B 24 (1981) 1725.

[42] A.R. Miedema, P.F. de Châtel, F.R. de Boer, Physica 100B $+\mathrm{C}(1980) 1$.

[43] Ch. Linsmeier, AIP Conf. Proc. 740 (2004) 182.

[44] Landolt-Börnstein, Numerical Data and Functional Relationships in Science and Technology New Series, Ed. O. Madelung, Group III "Crystal and Solid State Physics", V. 26 - Diffusion in Solid Metals and Alloys, Berlin (1990).
[45] A. Wiltner, Ch. Linsmeier, T. Jacob, J. Chem. Phys. 129 (2008) 084704.

[46] A.F. Holleman, E. Wiberg, Lehrbuch der Anorganischen Chemie, 101st ed., Berlin (1995).

[47] T.B. Massalski, H. Okamoto, P.R. Subramanian, L. Kacprzak, Binary Alloy Phase Diagrams, 2nd ed., Version 1.0, ASM International, Materials Park, Ohio (1996).

[48] R. Haerle, E. Riedo, A. Pasquarello, A. Baldereschi, Phys. Rev. B 65 (2001) 5101. 